\title{
A STUDY ON THE CLINICO-EPIDEMIOLOGICAL ASPECTS AND EVIDENCE OF AUTOIMMUNITY IN PATIENTS WITH MULTIPLE DRUG ALLERGY SYNDROME
}

\author{
Sukumarakurup Sreekanth ${ }^{1}$, Najeeba Riyaz ${ }^{2}$, Sarita Sasidharanpillai ${ }^{3}$, Manikoth Payyanadan Binitha ${ }^{4}$, Kunnummal Muhammed ${ }^{5}$ \\ Olassery Kalathingal Reena-Mariyath ${ }^{6}$, Padma Sharanya ${ }^{7}$, Fathima Machingal Salima ${ }^{8}$ \\ ${ }_{1}^{1}$ Associate Professor, Department of Dermatology and Venereology, Government Medical College, Kozhikode, Kerala. \\ 2 Professor and HOD, Department of Dermatology and Venereology, Government Medical College, Kozhikode, Kerala. \\ ${ }^{3}$ Associate Professor, Department of Dermatology and Venereology, Government Medical College, Kozhikode, Kerala. \\ ${ }_{4}^{4}$ Professor, Department of Dermatology and Venereology, Government Medical College, Kozhikode, Kerala. \\ ${ }^{5}$ Additional Professor, Department of Dermatology and Venereology, Government Medical College, Kozhikode, Kerala. \\ ${ }^{6}$ Assistant Professor, Department of Dermatology and Venereology, Government Medical College, Kozhikode, Kerala. \\ ${ }_{7}^{7}$ Junior Resident, Department of Dermatology and Venereology, Government Medical College, Kozhikode, Kerala. \\ 8Junior Resident, Department of Dermatology and Venereology, Government Medical College, Kozhikode, Kerala.
}

\section{ABSTRACT}

\section{BACKGROUND}

Though multiple drug allergy syndrome or multiple drug hypersensitivity syndrome has been described as a distinct entity, not much data is available on the same, especially in Indian literature.

\begin{abstract}
AIMS
To study the incidence of multiple drug allergy syndrome among patients with cutaneous adverse drug reaction (CADR) attending a referral centre and to study its clinical and epidemiological features and evidence of autoimmunity.

\section{METHODS}

All patients admitted in Dermatology ward of our tertiary care hospital for a 2-year period from 1st August 2012 to $31^{\text {st }}$ July 2014 with CADR were studied for documented evidence of CADR to two or more unrelated drugs. The subjects were included in this prospective study after clearance from institutional ethics committee and written informed consent from study subjects. The cases identified as multiple drug allergy syndrome were studied in a more detailed manner and were evaluated for comorbidities with special reference to autoimmune diseases and human immunodeficiency virus infection. The clinical patterns and the common offending drugs were studied.
\end{abstract}

\section{RESULTS}

During the two-year study period, 10 out of the 94 patients with CADR included in the study were found to be belonging to the category of multiple drug allergy syndrome (After strict scrutiny) with a clear female predilection (70\%). The different reaction patterns in patients with multiple drug allergy syndrome were fixed drug eruption, urticaria, erythema multiforme, angioedema, drug reaction with eosinophilia and systemic symptoms (DRESS) and exfoliative dermatitis. Six out of ten patients with multiple drug allergy syndrome showed positivity on antinuclear antibody profile and two were diagnosed to have systemic lupus erythematosus.

\section{CONCLUSIONS}

A $10.6 \%$ of those admitted with CADR have multiple drug allergy syndrome, which exists as a separate entity. Female predominance and the evidence of autoimmune manifestations in the majority underscores the need to evaluate the role of autoimmunity in precipitating allergy to multiple drugs. Large prospective studies with age and sex matched controls in different population groups may throw light on the less known aspects of this syndrome. A decision to investigate all patients with allergy to multiple drugs for evidence of autoimmunity may be worthwhile.

\section{KEYWORDS}

Multiple Drug Allergy Syndrome, Multiple Drug Hypersensitivity Syndrome, Autoimmunity.

HOW TO CITE THIS ARTICLE: Sukumarakurup Sreekanth, Najeeba Riyaz, Sarita Sasidharanpillai, Manikoth Payyanadan Binitha, Kunnummal Muhammed, Olassery Kalathingal Reena-Mariyath, Padma Sharanya, Fathima Machingal Salima. "A Study on the Clinico-epidemiological Aspects and Evidence of Autoimmunity in Patients with Multiple Drug Allergy Syndrome." Journal of Evolution of Medical and Dental Sciences 2015; Vol. 4, Issue 95, November 26; Page: 16030-16035, DOI: $10.14260 /$ jemds/2015/2340.

Financial or Other, Competing Interest: None.

Submission 10-11-2015, Peer Review 11-11-2015,

Acceptance 19-11-2015, Published 24-11-2015.

Corresponding Author:

Dr. Sreekanth $S$,

Associate Professor,

Department of Dermatology and Venereology,

Government Medical College, Kozhikode,

Kerala.

E-mail: drsreekanths75@gmail.com

DOI:10.14260/jemds/2015/2340.

\section{INTRODUCTION}

Adverse Drug Reactions (ADR) contribute to a significant portion of case load in referral centres. Documented literature suggest that $1 \%-10 \%$ of patients with drug allergy manifest hypersensitivity to multiple unrelated drugs.[1,2] In 1989 Sullivan et al.[3] described multiple drug allergy syndrome (Also known as multiple drug hypersensitivity syndrome) as a distinct entity where the affected shows allergies to two or more chemically different drugs. 
Later authors stressed that it has to be differentiated from cross reactivity and flare-up reactions. ${ }^{2]}$ Cross reactivity arises from structural similarities, common metabolic pathways or pharmacologic mechanisms shared by different drugs.

By this definition, a patient allergic to different groups of non-steroidal anti-inflammatory drugs (NSAID) cannot be considered as having multiple drug allergy since all these drugs share common pharmacologic mechanisms. Flare up reactions are defined as the exacerbation of an existing drug hypersensitivity by introduction of an unrelated drug. ${ }^{[2]}$

This has been reported in Severe Cutaneous Adverse Reactions (SCAR), especially Drug Reaction with Eosinophilia and Systemic Symptoms (DRESS) and is attributed to the immune activation induced by a severe drug reaction, which predisposes the patient to manifest hypersensitivity to otherwise well tolerated drugs.

This sensitisation to the second drug may be temporary, i.e., the same drug will be well tolerated once the milieu of immune activation (Flare up reaction) subsides or may be permanent resulting in allergy to multiple drugs. In the absence of appropriate drug allergy work up (Patch test, lymphocyte transformation test etc.), it is difficult to distinguish between flare up reactions and multiple drug allergy. Moreover multiple drug allergies can occur either simultaneously or sequentially over a period of months or years.[2]

Various risk factors documented for developing multiple drug allergy are female sex, allergy to NSAID, human immunodeficiency virus infection, systemic lupus erythematosus and history of a severe drug reaction, especially DRESS.[1,2,4,5,6]

Not many studies are available on the clinical pattern of multiple drug allergy syndrome, especially in Indian population. In this background, we decided to carry out a prospective study on the incidence of allergy to multiple unrelated drugs among patients with cutaneous adverse drug reaction (CADR) attending the Dermatology Department of our institution and to study its clinical and epidemiological features and co-existing autoimmune manifestations.

\section{MATERIALS AND METHODS}

The patients who were admitted in the Dermatology Department of our tertiary care institution with probable Cutaneous Adverse Drug Reaction (CADR) as per World Health Organisation causality assessment,[7] (Drug rechallenge was not carried out) from August $1^{\text {st }} 2012$ to July $31^{\text {st }} 2014$ were included in the study and specifically enquired about similar history in the past.

Those who had documented evidence of probable or certain CADR to one or more chemically and pharmacologically unrelated drugs were studied in detail, especially for evidence of autoimmune diseases and human immuneodeficiency virus infection. The study was conducted after obtaining clearance from institutional ethics committee and written informed consent from individual study subject. Documented evidence of drug allergy confirmed by oral rechallenge test or documented evidence of ADR to the same drug on two separate occasions was considered as certain ADR to a particular drug.
All patients with CADR, at least to one drug were kept under regular followup throughout the study period. If any of the patients who presented to us with CADR to a single drug, developed allergy to an unrelated drug after resolution of the initial reaction, during the study period he/she was subsequently included in the group with CADR to multiple drugs.

Exclusion Criteria: Those with history of chronic urticaria, spontaneous angioedema and patients who gave history of allergic manifestations like urticaria or angioedema to food items or environmental agents were excluded from the study. Patients who manifested ADR following ayurvedic, homeo or indigenous treatment were also excluded from the study.

Patients who showed allergic manifestations to various NSAIDS alone were not considered as belonging to the group with CADR to multiple drugs. Those who did not have documented evidence, confirmatory of probable or certain adverse reaction to an unrelated drug were also excluded from the group with CADR to multiple drugs. If data regarding previous drug reaction was insufficient (If offending drug, clinical manifestations and type of ADR not well documented), such cases were also excluded from this group. Patients who manifested exacerbation of existing clinical manifestations or who developed a different type of reaction to an unrelated drug during treatment for an ADR (Before complete resolution of original ADR) were also excluded from this group.

A pre-set proforma was used to collect data regarding age, sex, age of onset of initial ADR, previous episodes of ADR, offending drugs and the reaction pattern during each episode. Information regarding family history of drug reactions and autoimmune diseases were noted in individual study subject. Any co-morbidities were carefully documented with special reference to Human Immunodeficiency Virus (HIV) infection and autoimmune diseases.

A detailed information on co-administered drugs were collected. Complete hemogram, urine microscopy, peripheral smear for atypical cells and blast forms, random blood sugar estimation, renal and liver function tests, serum electrolytes, serology for rheumatoid factor, HIV and hepatitis A, B and C viruses, chest radiography, ultra-sonogram of abdomen and pelvis, antinuclear antibody profile and thyroid function test were performed in each patient with multiple drug allergy syndrome and the results were carefully documented. Infections due to herpes simplex viruses 1 and 2 and mycoplasma were ruled out in all erythema multiforme patients through serology.

Patients showing positivity in ANA profile without any features to diagnose collagen vascular diseases were re-tested 3 months after resolution of ADR and considered to have positive ANA profile only if they tested positive for the same antinuclear antibody with ++ titre on both occasions. Skin, mucosal and lymph node biopsies, computerised tomogram of abdomen and thorax, bone marrow analysis, electromyogram, muscle enzyme analysis and muscle biopsy were done only when indicated. All patients with CADR were kept under regular followup throughout the study period. Any new drug allergy detected during the same was noted. 
Data was analysed and an attempt was made to study the incidence of multiple drug allergy syndrome, and its clinico-epidemiological profile and evidence of autoimmunity.

\section{RESULTS}

During the two-year study period, 94 patients were admitted in the Dermatology ward of our institution with probable ADR. Of these, nine patients (Six females and three males) had documented evidence of CADR to at least one other unrelated drug in the past. One female patient, who presented with DRESS two weeks after starting acetaminophen and ranitidine for knee joint pain with no previous episodes of ADR, was later considered as having multiple drug allergy syndrome, as she manifested exfoliative dermatitis to diclofenac sodium and alendronate on two other occasions 3 months and 6 months respectively after complete resolution of DRESS. Irrespective of the offending drug, the reaction pattern remained the same in the remaining nine, i.e., fixed drug eruption in three cases (Two females and one male, [Figure 1]), urticaria in three cases (Two females and one male, [Figure 2]), erythema multiforme with oral eosions in two cases (One male and one female, [Figure 3]) and angioedema [Figure 4] in one female patient.

Age of the patients with multiple drug reaction syndrome ranged from 32-67 years with a mean of 48 years. The age of onset of ADR was in the fourth decade of life in 4 patients (two males and two females); in the second decade in 2 (One male and one female); in the fifth and seventh decade in 2 others (both females). Two patients could not recollect the age of onset of ADR.

The age, sex, offending drugs, type of reaction, comorbidities and ANA profile in cases with multiple drug allergy syndrome were as shown in Table 1. Four females and one male with multiple drug allergy syndrome gave history of recurrent joint pain. Four of them had recurrent knee and hip joint pain, while one female patient gave history of recurrent shoulder joint pain. One patient with no prior history of drug or food allergy, manifested urticaria to diclofenac sodium prescribed for hip joint pain during chikungunya infection in 2006.

Since then she has experienced chronic knee and hip joint pain and manifested urticaria following various nonsteroidal anti-inflammatory drugs, tranexamic acid (Taken for menorhhagea) and ranitidine (Taken for acid peptic disease) on separate occasions. Two more females with recurrent joint pain also manifested allergic reaction for the first time after analgesics taken for joint pain. In the other two with recurrent joint pain (Case No: 5 and 8, Table 1), history of drug allergy preceeded the joint symptoms by 3 years and 4 years respectively. Erythema multiforme with oral erosions was the ADR observed in both. Lupus nephritis was diagnosed 5 years after the initial episode of drug reaction in the male patient and the female patient developed Systemic Lupus Erythematosus (SLE) 9 years after the initial ADR. Antinuclear antibody profile revealed positivity for antidsDNA, anti-Sm, anti-nucleosome, anti- $\mathrm{U}_{1} \mathrm{RNP}$ and anti-Ku antibodies in the male patient, while the female SLE patient showed positivity for anti-dsDNA and anti-Sm antibodies.

Antinuclear antibody profile detected positivity (Table 1) in four others (All females). All had titre of ++ or more. All except one (Table 1, Case No: 2) of those who had positivity in antinuclear antibody profile suffered from recurrent joint pain of more than three years. The female patient who had recurrent shoulder joint pain was evaluated for possible polymyositis as she had shoulder muscle tenderness and anti-Jo-1 positivity. Electromyogram was suggestive of myopathic weakness. But the muscle enzymes were within normal limits and the muscle biopsy was unremarkable. Her joint symptoms improved with hydroxy chloroquin. We have kept her under followup.

The patient who attributed the onset of ADR to chikungunya infection, also gave history suggestive of Raynaud's phenomenon since the viral infection episode. Positivity for anti-centromere and anti-SS-A antibody positivity in her prompted us to undertake a detailed evaluation. At present she does not have any clinical evidence to indicate a diagnosis of scleroderma, SLE or rheumatoid arthritis. She is managed with nifedipine $10 \mathrm{mg}$ twice daily and massage with emollients along with advice to minimise exposure to cold and vibratory stimuli.

Thyroid function status was normal in all except two female patients who had hypothyroidism. These two showed urticarial reaction to different drugs. Diagnosis and management of the endocrine abnormality preceded the first episode of ADR by 2 years in one whereas in the other ADR preceded the diagnosis of hypothyroidism by 5 years. Both patients had positivity detected on ANA profile.

Serology for HIV infection and rheumatoid factor was negative in all the patients with multiple drug allergy syndrome. None of them were diabetic or hypertensive.

\section{DISCUSSION}

During the two year study period, $10.6 \%$ of those admitted in our institution with CADR were found to be sensitive to multiple unrelated drugs which was comparable to previous reports.[1,2] The female predilection observed in our study population $(70 \%)$ was consistent with the available literature.[1] The mean age of our study population was slightly lower than that observed in previous studies (51-62 yrs).[4,8] Similar to our observations, others also noted multiple drug allergy to be rare in children; but Atanaskovic et al. in their study on drug reaction in pediatric population documented that $2.5 \%$ of those with suspected drug allergy were allegic to multiple drugs.[9]

The reaction patterns observed were comparable to existing data on multiple drug allergy.[1] Unlike described in literature, most of the patients with multiple drug allergy syndrome in our study $(90 \%)$ showed similar pattern of reaction irrespective of the culprit drug.[2] Unlike our study, some other studies found antiepileptics to be one of the offenders. ${ }^{[9,10]}$ Nine out of ten patients with multiple drug allergy syndrome in our study group showed allergic reaction to one or more NSAIDs and in six of them the first episode of drug allergy was precipitated by a NSAID.

This was consistent with the previous reports of allergy to NSAID, being an independant risk factor for multiple drug allergy.[1] Allergic reaction to $\mathrm{H}_{1}$ blockers noted in some of our patients was also reported earlier. ${ }^{[4,8]}$ The antibiotic sensitivity noted in $50 \%$ of our cases was in concordance with previous studies. ${ }^{44,8,10]}$ 
Two more episodes of drug reactions within six months of resolution of DRESS noted in one of our patients was consistent with the earlier reports citing severe drug reaction as a predisposing factor for multiple drug allergy. Pichler et al. proposed immune activation induced by severe drug reaction to be an inciting factor for neo-sensitisation to other drugs. [2]

The increased risk of drug reactions noted in viral infections was also explained by similar immune activation and one of our patients attributed the onset of drug allergy to chikungunya infection. ${ }^{[2]}$

Coexisting SLE in two of our patients was in concordance with literature.[11] Interestingly both patients had erythema multiforme precipitated by different drugs, some years before a diagnosis of SLE was made. The possibility of Rowell's syndrome was unlikely as anti-Ro and anti-La antibodies were negative in both; in addition chilblain lesions were absent and serology for rheumatoid factor was negative.[12] Moreover both patients had documented evidence of clear temporal relationship between the offending drugs and the ADR with prompt response to withdrawal of the suspected medication, supportive care and short course of systemic steroids.

Out of the 10 patients found to have multiple drug allergy syndrome, 6 were having positive ANA profile (60\%). Whether the underlying autoimmune diathesis was the cause or the effect of multiple drug allergy remains unclear. The possibility of arthralgia (Noted in 5/6 patients with positive antinuclear antibodies) being a pre-runner of collagen vascular disease needs further study. Diagnosis of SLE in two patients along with the possibility of evolving collagen vascular disease in other 2 (Case No 6 and 9, Table 1) of the total 6 cases with positive ANA profile supports the hypothesis put forth by Pichler et al., i.e., an immune reaction to a drug could be the result of a deficient tolerance mechanism of the individual against small chemical compounds and the particular patient may be at risk for other drug allergies as well as autoimmunity.[2]

Among the patients admitted with CADR, in patients with allergy to single drug/flareup reaction/no documented evidence of multiple drug allergy, ANA profile was not routinely done. But 15 out of 84 such patients had underwent testing for antinuclear antibodies and rheumatoid factor as part of the work up during hospital stay or in recent past (Table 2). Three out of $15(20 \%)$ had positive ANA profile with ++ titre in two and one of them was already diagnosed to have rheumatoid arthritis. A repeat testing done after 6 months in the lamotrigine induced DRESS patient returned the same report. This was not available in the other two. Whether the inflammatory arthritis in two of them (Case 10 and 15, Table 2) along with severe drug reaction and the positive antinuclear antibody status in all three has placed them at risk for multiple drug allergy remains to be seen.

One of the limitations of our study was that drug allergy work up (Patch test, lymphocyte transformation test etc.), was not done. But there is no consensus on whether a drug allergy work up should be made mandatory before a diagnosis of multiple drug hypersensitivity syndrome is made. Some advocate that the term 'multiple drug hypersensitivity syndrome' should be restricted to those cases confirmed by proper drug allergy work up and people who show negative drug allergy work up should be categorised as multiple drug intolerance syndrome.[4] Another view is that relying too much on drug allergy work up may result in missing at least some of the multiple drug hypersensitivity syndrome as these tests do not always detect all true positives. Skin or in vitro tests may be negative in spite of a very suggestive history and symptoms. ${ }^{[2]}$ Moreover even patch testing can provoke life threatening reactions in SCAR and in vitro drug testing facilities are not available in all centres.

The main advantage of lymphocyte transformation test is its applicability with many different drugs in different immune reactions, as drug-specific T-cells are almost always involved in drug hypersensitivity reactions. Its disadvantage is that the test is cumbersome and technically demanding. The method is not unequivocally accepted, it is necessary to carry out a systematic evaluation of its sensitivity and specificity to make the test more widely appreciated.[13]

\section{CONCLUSION}

Multiple drug allergy syndrome exists as a separate entity. Among those admitted with CADR, 10.6\% have multiple drug allergy syndrome. Female predominance and the evidence of autoimmune manifestations in the majority, underscores the need to evaluate the role of autoimmunity in precipitating allergy to multiple drugs. Large prospective studies with age and sex matched controls in different population groups may throw light on the less known aspects of this syndrome. Although further evidence is required to confirm, a decision to investigate all patients in clinical practice with allergy to multiple drugs for evidence of autoimmunity may be worthwhile for an early diagnosis of collagen vascular disease.

\section{REFERENCES}

1. Asero R. Multiple drug allergy syndrome: a distinct clinical entity. Curr Allergy Rep. 2001 Jan;1:18-22.

2. Pichler WJ, Daubner B, Kawabata T. Drug hypersensitivity: Flare-up reaction, cross reactivity and multiple drug hypersensitivity. J Dermatol 2011;38: 216-21.

3. Sullivan T, Remedios C, Ong M, Gilliam LK. Studies of the multiple drug allergy syndrome. J Allergy Clin Immunol 1989;83:270.

4. Chiriac AM, Demoly P. Multiple Drug Hypersensitivity Syndrome. Curr Opin Allergy Clin Immunol 2013;13:323-9.

5. Coopman SA, Johnson RA, Platt R, Stern RS. Cutaneous disease and drug reactions in HIV infection. N Engl J Med 1993;328:1670-1674.

6. Petri M, Allbritton J. Antibiotic allergy in systemic lupus erythematosus: a case control study. J Rheumatol 1992;19:265-269.

7. Edwards IR, Aronson JK. Adverse drug reactions: Definitions, diagnosis, and management. Lancet 2000;356:1255-9.

8. Kanny G, Pichler W, Morisset M, Franck P, Marie B, Kohler $\mathrm{C}$ et al. $\mathrm{T}$ cell-mediated reactions to iodinated contrast media: evaluation by skin and lymphocyte activation tests. J Allergy Clin Immunol 2005;115:179185 
9. Atanaskovic-Markovic M, Gaeta F, Gavrovic-Jankulovic M, Cirkovic-Velickovic T, Valluzzi RL, Romano A. Diagnosing multiple drug hypersensitivity in children. Pediatr Allergy Immunol 2012;23:785-791.

10. Gex-Collet C, Helbling A, Pichler WJ. Multiple drug hypersensitivity-proof of multiple drug hypersensitivity by patch and lymphocyte transformation tests. J Investig Allergol Clin Immunol 2005;15:293-296.
11. Aceves-Avila FJ, Benites-Godínez V. Drug allergies may be more frequent in systemic lupus erythematosus than in rheumatoid arthritis. J Clin Rheumatol 2008;14: 261-3.

12. Zeitouni NC, Funaro D, Cloutier RA, Gagné E, Claveau J. Redefining Rowell's syndrome. $\mathrm{Br} \mathrm{J}$ Dermatol 2000;142:343-6.

13. Makó S, Lepesi-Benko R, Marschalkó M, Soós G, Kárpáti S. Diagnostic methods for confirming drug allergy- the lymphocyte transformation test in dermatology. Orv Hetil 2008 15;149(24):1107-14.

\begin{tabular}{|c|c|c|c|c|c|c|}
\hline $\begin{array}{c}\text { Serial } \\
\text { No }\end{array}$ & Age & Sex & $\begin{array}{l}\text { Offending } \\
\text { Drugs }\end{array}$ & $\begin{array}{c}\text { Type of } \\
\text { Drug Reaction }\end{array}$ & Co-morbidity & $\begin{array}{c}\text { Antinuclear } \\
\text { Antibody Profile }\end{array}$ \\
\hline 1 & 32 & M & $\begin{array}{l}\text { Diclofenac sodium, } \\
\text { Ibuprofen, Cetirizine. }\end{array}$ & Urticaria & None & Negative \\
\hline 2 & 56 & $\mathrm{~F}$ & $\begin{array}{c}\text { Acetaminophen, } \\
\text { Cetirizine, Amoxycillin }\end{array}$ & Fixed drug eruption & None & $\begin{array}{l}\text { Anti-PCNA antibody } \\
\text { positive }\end{array}$ \\
\hline 3 & 53 & $\mathrm{~F}$ & $\begin{array}{l}\text { Acetaminophen, } \\
\text { Omeprazole }\end{array}$ & Angioedema & None & Negative \\
\hline 4 & 57 & M & $\begin{array}{l}\text { Cotrimoxazole, } \\
\text { Ciprofloxacin }\end{array}$ & Fixed drug eruption & None & Negative \\
\hline 5 & 40 & M & $\begin{array}{c}\text { Ampicillin, Diclofenac } \\
\text { sodium, Ibuprofen, } \\
\text { Cephalosporin, Ketorolac. }\end{array}$ & $\begin{array}{l}\text { Erythema multiforme } \\
\text { with oral erosions }\end{array}$ & $\begin{array}{l}\text { Chronic hip and knee } \\
\text { joint pain, Lupus } \\
\text { nephritis }\end{array}$ & $\begin{array}{c}\text { Anti-dsDNA, } \\
\text { antinucleosome, } \\
\text { antihistone,, anti- } \\
\mathrm{U}_{1} \text { RNP and anti-Ku } \\
\text { antibodies positive }\end{array}$ \\
\hline 6 & 52 & $\mathrm{~F}$ & $\begin{array}{c}\text { Ciprofloxacin, Mefenamic } \\
\text { acid, Acetaminophen, } \\
\text { Diclofenac sodium, } \\
\text { Cefadroxyl }\end{array}$ & $\begin{array}{l}\text { Fixed drug reaction } \\
\text { affecting multiple sites } \\
\text { with oral erosions }\end{array}$ & $\begin{array}{l}\text { ?dermatomyositis, } \\
\text { Chronic shoulder } \\
\text { joint pain }\end{array}$ & $\begin{array}{l}\text { Anti- Jo-1 antibody } \\
\text { positive }\end{array}$ \\
\hline 7 & 42 & $\mathrm{~F}$ & $\begin{array}{c}\text { Diclofenac sodium, } \\
\text { Ampicillin, Cetirizine. }\end{array}$ & Urticaria & $\begin{array}{l}\text { Chronic hip and knee } \\
\text { joint pain, } \\
\text { Hypothyroidism }\end{array}$ & $\begin{array}{l}\text { Anti-Ku and anti-Mi2 } \\
\text { antibodies positive }\end{array}$ \\
\hline 8 & 45 & $\mathrm{~F}$ & $\begin{array}{c}\text { Isoniazide, Diclofenac } \\
\text { sodium, Ibuprofen, } \\
\text { Ketorolac, Etoricoxib }\end{array}$ & $\begin{array}{l}\text { Erythema multiforme } \\
\text { with oral erosions }\end{array}$ & $\begin{array}{l}\text { Chronic knee and hip } \\
\text { joint pain }\end{array}$ & $\begin{array}{l}\text { Anti-dsDNA and anti- } \\
\text { sm antibodies positive }\end{array}$ \\
\hline 9 & 36 & $\mathrm{~F}$ & $\begin{array}{l}\text { Acetaminophen, } \\
\text { Mefenamic acid, } \\
\text { Tranexamic acid, } \\
\text { Ketorolac, Ranitidine }\end{array}$ & Urticaria & $\begin{array}{l}\text { Chronic hip and knee } \\
\text { joint pain, } \\
\text { Hypothyroidism }\end{array}$ & $\begin{array}{c}\text { Anti-Ro and anti- } \\
\text { centromere antibodies } \\
\text { positive }\end{array}$ \\
\hline \multirow{2}{*}{10} & \multirow{2}{*}{67} & \multirow{2}{*}{$\mathrm{F}$} & $\begin{array}{l}\text { Acetaminophen, } \\
\text { Ranitidine, } \\
\end{array}$ & DRESS & \multirow{2}{*}{ None } & \multirow{2}{*}{ Negative } \\
\hline & & & $\begin{array}{l}\text { Diclofenac sodium, } \\
\text { Alendronate }\end{array}$ & Exfoliative dermatitis & & \\
\hline
\end{tabular}

Drug producing reaction at the time of inclusion in the study is written in bold letters. DRESS: Drug Reaction with Eosinophilia and Systemic Symptoms. 


\begin{tabular}{|c|c|c|c|c|c|c|c|}
\hline $\begin{array}{c}\text { Serial } \\
\text { No }\end{array}$ & Age & Sex & Offending Drugs & $\begin{array}{c}\text { Type of Drug } \\
\text { Reaction }\end{array}$ & $\begin{array}{l}\text { Disease for which } \\
\text { Drug Taken }\end{array}$ & Co-morbidity & $\begin{array}{c}\text { Antinuclear } \\
\text { Antibody Profile }\end{array}$ \\
\hline 1 & 41 & $\mathrm{~F}$ & $\begin{array}{c}\text { Antituberculous } \\
\text { treatment }\end{array}$ & $\begin{array}{l}\text { Exfoliative } \\
\text { dermatitis }\end{array}$ & $\begin{array}{c}\text { Pulmonary } \\
\text { Tuberculosis }\end{array}$ & None & Negative \\
\hline 2 & 45 & M & Allopurinol & SJS & Hyperuricemia & None & Negative \\
\hline 4 & 35 & $\mathrm{M}$ & Acetaminophen & Urticaria & Fever & None & Negative \\
\hline 5 & 52 & $\mathrm{~F}$ & Dapsone & DRESS & $\begin{array}{l}\text { Mid-borderline } \\
\text { leprosy }\end{array}$ & None & Negative \\
\hline 6 & 36 & $\mathrm{~F}$ & Diclofenac sodium & Urticaria & Migraine & None & Negative \\
\hline 7 & 32 & $\mathrm{M}$ & Carbamazepine & DRESS & Seizure disorder & None & Negative \\
\hline 8 & 33 & M & Cefuroxime & DRESS & $\begin{array}{l}\text { Lower respiratory } \\
\text { tract infection }\end{array}$ & $\begin{array}{l}\text { Chronic back } \\
\text { pain }\end{array}$ & Negative \\
\hline \multirow[b]{2}{*}{$* 9$} & \multirow[b]{2}{*}{22} & \multirow[b]{2}{*}{$\mathrm{F}$} & Carbamazepine, & TEN & \multirow[b]{2}{*}{ Seizure Disorder } & \multirow[b]{2}{*}{ None } & \multirow[b]{2}{*}{ Negative } \\
\hline & & & $\begin{array}{l}\text { cefoperazone } \\
\text { sulbactam }\end{array}$ & Angioedema & & & \\
\hline$* 10$ & 33 & M & $\begin{array}{l}\text { Carbamazepine, } \\
\text { Aceclofenac }\end{array}$ & SJS & $\begin{array}{l}\text { Peripheral } \\
\text { neuropathy }\end{array}$ & Sacroiliitis & $\begin{array}{l}\text { Anti SSA and anti } \\
\text { Ro positive }(+)\end{array}$ \\
\hline *11 & 23 & M & $\begin{array}{l}\text { Ciprofloxacin, } \\
\text { Diclofenac sodium, } \\
\text { Cefuroxime }\end{array}$ & Urticaria & Leg abscess & None & Negative \\
\hline 12 & 24 & $\mathrm{~F}$ & Lamotrigine & DRESS & Seizure disorder & None & $\begin{array}{c}\text { Anti La positive } \\
(++)\end{array}$ \\
\hline 13 & 46 & $\mathrm{~F}$ & Sodium valproate & DRESS & Bipolar disorder & None & Negative \\
\hline 14 & 52 & $\mathrm{~F}$ & $\begin{array}{c}\text { Antituberculous } \\
\text { treatment }\end{array}$ & DRESS & $\begin{array}{l}\text { Pulmonary } \\
\text { tuberculosis }\end{array}$ & None & Negative \\
\hline 15 & 50 & $\mathrm{~F}$ & Salazopyrin & DRESS & Rheumatoid arthritis & None & $\begin{array}{c}\text { Anti La positive } \\
(++)\end{array}$ \\
\hline
\end{tabular}

* Patients developing exacerbation of existing drug allergy or appearance of new drug allergy on introduction of an unrelated drug before complete resolution of a cutaneous adverse drug reaction-? Flare up reaction? Multiple drug allergy syndrome.

SJS: Stevens Johnson Syndrome. DRESS: Drug Reaction with Eosinophilia and Systemic Symptoms. TEN: Toxic Epidermal Necrolysis.

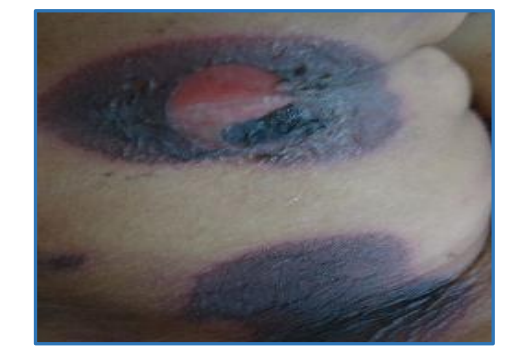

Fig. 1: Showing Fixed Drug Eruption on the Neck of a Patient

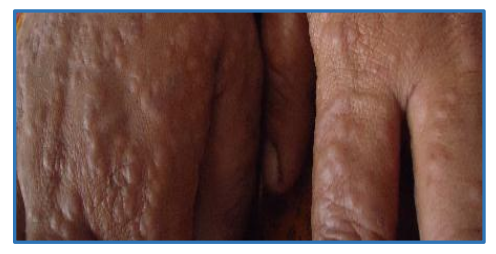

Fig. 2: Small sized Urticarial Lesions in Extremities

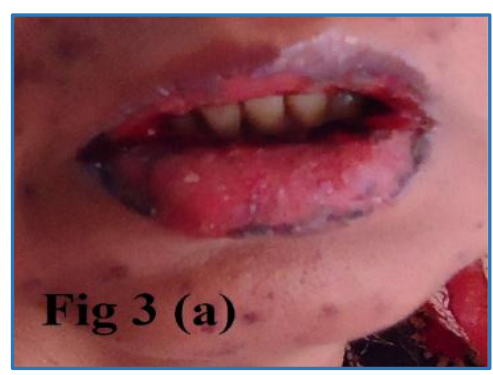

Fig. 3 (a): Showing Oral Erosions and Erythema Multiforme Lesions on the Face

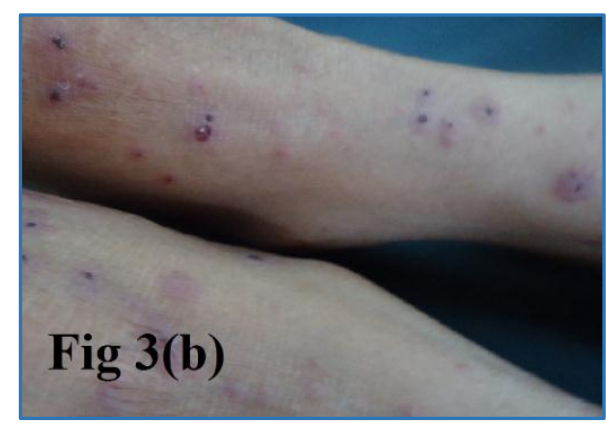

Fig. 3 (b): Showing Erythema Multiforme Lesions on the Leg of the Same Patient.

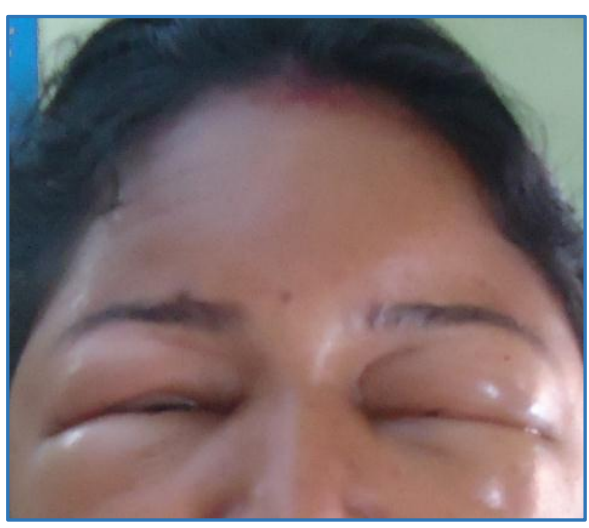

Fig. 4: Drug Induced Angioedema in a Patient. 